\title{
Milk fat response and milk fat and urine biomarkers of microbial nitrogen flow during supplementation with 2-hydroxy-4-(methylthio)butanoate
}

\author{
M. Baldin, ${ }^{1 *}$ H. A. Tucker, ${ }^{2}$ and K. J. Harvatine ${ }^{1} \dagger$ \\ ${ }^{1}$ Department of Animal Science, Penn State University, University Park 16802 \\ ${ }^{2}$ Novus International Inc., St. Charles, MO 63304
}

\section{ABSTRACT}

2-Hydroxy-4-(methylthio)butanoate (HMTBa) is a methionine analog that has been observed to attenuate biohydrogenation (BH)-induced milk fat depression (MFD), possibly through reducing the shift to altered $\mathrm{BH}$ pathways. It has also been suggested that HMTBa increases microbial protein synthesis in the rumen. Our objectives were to stimulate $\mathrm{BH}$-induced MFD and (1) verify HMTBa inhibition of BH-induced MFD and changes in milk fatty acids (FA) associated with altered rumen $\mathrm{BH}$ (i.e., trans-10 C18:1); and (2) determine the effect of HMTBa on milk fat (i.e., odd- and branchedchain FA) and urine biomarkers related to microbial $\mathrm{N}$ flow. Twenty-four multiparous cows $(45.6 \pm 8.5 \mathrm{~kg}$ of milk/d; mean \pm standard deviation) and 12 primiparous cows $(32.8 \pm 3.1 \mathrm{~kg}$ of milk/d) were arranged in a crossover design. Treatments were unsupplemented control and HMTBa fed at $0.1 \%$ of diet dry matter intake. The experiment was $80 \mathrm{~d}$ and included a $10-\mathrm{d}$ pretrial covariate period. Each experimental period included 2 phases that differed in risk for $\mathrm{BH}$-induced MFD, including a 28 -d low-risk phase $(31.6 \%$ neutral detergent fiber, $21.8 \%$ starch, and no oil) and a 7 -d moderate-risk phase $(28.7 \%$ neutral detergent fiber, $28.1 \%$ starch, and $1.0 \%$ soybean oil). We found no interaction of treatment and parity. Milk fat yield (1.43 $\pm 0.51 \mathrm{~kg} / \mathrm{d})$ and milk fat trans-10 C18:1 $(0.42 \pm 0.08$ $\mathrm{g} / 100 \mathrm{~g}$ of FA) did not differ between treatments during the low-risk phase. However, during the moderate-risk phase, HMTBa maintained higher milk fat concentration (3.91 vs. $3.79 \%)$, tended to maintain higher milk fat yield (1.44 vs. $1.38 \mathrm{~kg} / \mathrm{d})$, and decreased milk fat trans-10 C18:1 (0.61 vs. 0.93\% FA) compared with control. Additionally, HMTBa increased milk fat concentration and secretion of odd- and branched-chain FA by

Received May 8, 2018.

Accepted December 14, 2018.

*Current address: Provimi North America, 10 Nutrition Way, Brookville, OH 45309.

†Corresponding author: kjh182@psu.edu
5.3 and $10.2 \%$, respectively, but urinary biomarkers of microbial $\mathrm{N}$ flow (i.e., purine derivatives) did not differ between treatments. However, rumen bacterial samples were not available to provide cow- or treatment-specific microbial protein-to-marker ratios, which is a critical source of variation. Additionally, transfer of odd- and branched-chain FA to milk is dependent on several factors that may affect interpretation of these biomarkers. In conclusion, HMTBa decreased absorption of alternate $\mathrm{BH}$ intermediates and maintained higher milk fat when feeding a diet with moderate-risk for MFD.

Key words: 2-hydroxy-4-(methylthio)butanoate, biohydrogenation, milk fat, odd- and branched-chain fatty acids

\section{INTRODUCTION}

Milk fat is very important to dairy farm efficiency and profitability (Bolotova, 2016); however, many dairy farms still experience milk fat depression (MFD) or have suboptimal level of milk fat synthesis. The biohydrogenation (BH) theory (Bauman and Griinari, 2003) of MFD is a unifying concept that mechanistically explains the inhibition of milk fat synthesis when feeding rations that are highly fermentable, high in UFA, and low in effective fiber. The BH theory attributes the causal mechanism to changes in ruminal $\mathrm{BH}$ pathways, which lead to increased formation and rumen outflow of specific bioactive fatty acids (FA) that inhibit mammary lipid synthesis. We recently observed that feeding the rumen-unprotected methionine analog 2-hydroxy4-(methylthio)butanoate (HMTBa) provided a mechanism to prevent or attenuate BH-induced MFD in high-producing cows (Baldin et al., 2018). Our data suggested a role for HMTBa in stabilizing rumen $\mathrm{BH}$ and preventing the shift to the altered $\mathrm{BH}$ pathway.

In continuous culture fermenters, HMTBa increased microbial protein yield by $10 \%$ and increased microbial efficiency (Vázquez-Añón et al., 2001). Recent research using ${ }^{15} \mathrm{~N}$ and reticular sampling reported a linear increase in microbial protein with HMTBa supplementation in lactating dairy cows (Lee et al., 2015). Increased 
microbial growth and mass may result in increased $\mathrm{BH}$ capacity and prevent the formation of bioactive FA that decrease milk fat (McKain et al., 2010).

Direct observation of microbial markers in digesta flow is the gold standard to quantify microbial protein synthesis (Broderick and Merchen, 1992), but it is an intensive approach (i.e., surgical cannulations, intensive sampling, and analysis of multiple markers) impractical for large trials in lactating cows. Hence, less costly and noninvasive alternative methods of predicting microbial protein yield have been sought. Milk odd- and branched-chain FA (OBCFA; e.g., C15:0, iso $\mathrm{C} 15: 0$, anteiso $\mathrm{C} 15: 0, \mathrm{C} 17: 0$, iso $\mathrm{C} 17: 0$, anteiso $\mathrm{C} 17: 0$, and $\mathrm{C} 17: 1$ ) originate from microbial production in the rumen or de novo synthesis in the mammary gland from odd- and branched-chain VFA (Vlaeminck et al., 2015) and have been suggested as potential biomarkers of ruminal microbial $\mathrm{N}$ flow (Cabrita et al., 2003; Vlaeminck et al., 2005). Similarly, purine derivatives (allantoin and uric acid) are the product of nucleic acid metabolism and, because the vast majority of the nucleic acid reaching the intestine of cows originates from ruminal microbes, urinary purine derivatives have been suggested as a predictor of microbial flow out of the rumen (Chen et al., 1992; Valadares et al., 1999). However, this indirect approach contains numerous assumptions and errors associated with changes in milk fat yield, creatinine prediction of urine excretion, the marker-to-microbial $\mathrm{N}$ ratio used, and variance of the prediction equation employed (see Firkins et al., 2006).

In the current study, we used an established dietary model to create $\mathrm{BH}$-induced MFD [lowered effective NDF, increased rumen UFA load, and higher starch (Rico and Harvatine, 2013; Baldin et al., 2018)] in cows supplemented with HMTBa. The objectives were (1) to verify $\mathrm{HMTBa}$ attenuation of $\mathrm{BH}$-induced MFD and altered rumen $\mathrm{BH}$ (i.e., trans-10 $\mathrm{C} 18: 1$ ) and (2) to determine the effect of HMTBa on milk and urine biomarkers of microbial $\mathrm{N}$ flow.

\section{MATERIALS AND METHODS}

\section{Treatments and Experimental Design}

All experimental procedures were approved by the Pennsylvania State University Institutional Animal Care and Use Committee. The experiment was conducted from November 2015 to February 2016 at the Pennsylvania State University Dairy Production Research and Teaching Center (University Park). Cows were housed in a sand-bedded freestall barn equipped with the Calan Broadbent Feeding System (American Calan Inc., Northwood, NH) for individual daily feeding and measurement of feed intake. Cows had continuous access to drinking water. All cows were trained to the feeding system before the start of a 10-d pretrial covariate period. Twelve primiparous (112 \pm 36 DIM; mean $\pm \mathrm{SD}$ ) and 24 multiparous (106 \pm 32 DIM; mean parity $=3$ ) cows were used in a crossover design. At the end of the pretrial period, when all cows were fed the low-risk diet with no HMTBa, the primiparous cows averaged $32.8 \pm 3.1 \mathrm{~kg}$ of milk and $23.5 \pm 3.0 \mathrm{~kg}$ of DMI and the multiparous cows averaged $45.6 \pm 8.5 \mathrm{~kg}$ of milk and $32.2 \pm 3.3 \mathrm{~kg}$ of DMI. Cows were paired within lactation by milk production at the end of the pretrial covariate period and randomly assigned to treatment sequence. Treatments were an unsupplemented control (CON) or HMTBa $(0.1 \%$ of diet DM). The HMTBa (Alimet; Novus International Inc., St. Charles, MO) was provided in a corn carrier (10\% HMTBa) and mixed in the TMR. An equal amount of the same ground corn carrier was added to the control treatment. Each period in the crossover design included 2 phases; in the first phase the basal diet was formulated to have a low risk of BH-induced MFD (d 1-28) and in the second phase the basal diet was formulated to have a moderate risk of BH-induced MFD (d 29-35). Risk for altered $\mathrm{BH}$ was increased by reducing diet NDF and increasing UFA and starch content (Table 1). Diet UFA were increased using a combination of rapidly available FA from soybean oil and more slowly available FA from roasted soybeans. The low-risk phase was $28 \mathrm{~d}$ to allow complete adaptation of the rumen to HMTBa, and the moderate-risk phases was $7 \mathrm{~d}$, as previous time course work has demonstrated that changes in milk fat and milk FA occur within 5 to $7 \mathrm{~d}$ (Rico and Harvatine, 2013). Diets were fed during pretrial and treatment period as a TMR once daily at $0700 \mathrm{~h}$ at $110 \%$ of expected daily intake.

\section{Sampling and Measurements}

Feed intake was measured daily. Cows were milked twice daily at 0600 and $1800 \mathrm{~h}$ and milk yield was determined by an integrated milk meter (AfiMilk, SAE Afikim, Afikim, Israel). The parlor was calibrated using a stall correction calculated using data from the entire herd ( $>200$ cows) over $7 \mathrm{~d}$. Correction factors were determined by modeling the effect of day, milking (a.m./p.m.), cow, and stall, excluding observations of experimental cows during treatment periods. Milk was sampled at both milkings once per week and was composited based on yield at each milking. Feed ingredients were sampled once per week and stored at $-20^{\circ} \mathrm{C}$, thawed at room temperature, dried at $55^{\circ} \mathrm{C}$ in a forced-air oven for $72 \mathrm{~h}$, and ground in a Wiley mill 
through a 1-mm screen (A. H. Thomas, Philadelphia, PA). Feed samples were composited within dietary phase (equal dry weight basis).

Body weight was analyzed as the average of 2 consecutive days at the end of the pretrial covariate period and on d 28 and 35 of each experimental period. Cows were weighed immediately after morning milking before feed delivery (Eziweigh 2 scale, Tru-test, Mineral Wells, TX). Three trained investigators determined BCS using a 5 -point scale $(1=$ thin, $5=$ fat; Wildman et al., 1982) at the end of the pretrial period and on $\mathrm{d} 28$ of each period. Three spot urine samples (about $100 \mathrm{~mL} /$ sampling) were collected on 2 consecutive days (1000 and $2200 \mathrm{~h}$ on $\mathrm{d} 1$ and $1400 \mathrm{~h}$ on $\mathrm{d} \mathrm{2}$ ) at the end of the pretrial period and on d 28 and 35 of each experimental period. Time points were selected to represent 3,7 , and $14 \mathrm{~h}$ postfeeding to fit between feeding and

Table 1. Ingredient and chemical composition of basal diets with low and moderate risk of biohydrogenation-induced milk fat depression (BH-MFD)

\begin{tabular}{lcc}
\hline & \multicolumn{2}{c}{ Risk of BH-MFD } \\
\cline { 2 - 3 } Item & Low & Moderate \\
\hline Ingredient, \% of DM & & \\
Corn silage & & \\
Alfalfa haylage $^{2}$ & 37.5 & 34.1 \\
Grass hay/straw $_{\text {Ground corn }}^{3}$ & 19.0 & 15.1 \\
Canola meal & 2.48 & 1.32 \\
Cottonseed hulls & 11.6 & 17.7 \\
Roasted soybeans & 13.2 & 14.0 \\
Mineral and vitamin mix & 3.30 & 3.30 \\
Soybean oil & 5.78 & 6.28 \\
NPN & 2.59 & 2.59 \\
Molasses & - & 1.00 \\
Analyzed composition, \% of DM & 0.41 & 0.41 \\
CP & 4.13 & 4.13 \\
ADF & & \\
aNDF & & \\
Starch & 16.5 & 16.0 \\
Total fatty acids & 22.5 & 20.3 \\
UFA $_{\text {peNDF }}^{7}$ & 31.6 & 28.7 \\
\hline
\end{tabular}

${ }^{1}$ Contained $41.1 \% \mathrm{DM}, 6.2 \% \mathrm{CP}$, and $35.0 \% \mathrm{NDF}$.

${ }^{2}$ Contained $46.5 \% \mathrm{DM}, 21.4 \% \mathrm{CP}$, and $44.0 \% \mathrm{NDF}$.

${ }^{3}$ Particle size between 500 and $700 \mu \mathrm{m}$.

${ }^{4}$ Composition (minimum, DM basis): $13.0 \%$ Ca; $0.38 \%$ P; $5.77 \%$ salt; $3.98 \% \mathrm{Cl} ; 2.15 \% \mathrm{Na} ; 4.60 \% \mathrm{Mg} ; 0.45 \% \mathrm{~K} ; 0.38 \% \mathrm{~S} ; 5.4 \mathrm{mg} / \mathrm{kg} \mathrm{Co} ; 358$ $\mathrm{mg} / \mathrm{kg} \mathrm{Cu} ; 13.4 \mathrm{mg} / \mathrm{kg} \mathrm{I} ; 188 \mathrm{mg} / \mathrm{kg} \mathrm{Fe} ; 1,071 \mathrm{mg} / \mathrm{kg} \mathrm{Mn} ; 6.67 \mathrm{mg} / \mathrm{kg}$ Se; $1,085 \mathrm{mg} / \mathrm{kg} \mathrm{Zn;} \mathrm{54,041} \mathrm{IU/kg} \mathrm{vitamin} \mathrm{A;} \mathrm{13,489} \mathrm{IU/kg} \mathrm{vitamin}$ D; $406 \mathrm{IU} / \mathrm{kg}$ vitamin E (Cargill Animal Nutrition, Minnetonka, MN). ${ }^{5}$ Coated urea (Optigen; Alltech Inc., Lexington, KY; $256 \%$ CP on DM basis).

${ }^{6}$ Ash-free NDF.

${ }^{7}$ Physically effective NDF. Analyzed using the Penn State Particle Separator (Kononoff et al., 2003). Particles remaining (\% of total) in the upper sieve, middle sieve, lower sieve, and bottom pan were 3.4, $39.5,19.0$, and 38 , respectively, for the low-risk diet; 1.3, 35.8, 18.6, and 44.4 , respectively, for the moderate-risk diet. milking times. Urine samples were immediately filtered through 2 layers of cheesecloth. Aliquots of the filtered urine were acidified by diluting 1 volume of urine with 4 volumes of $0.072 \mathrm{~N}$ sulfuric acid and stored at $-20^{\circ} \mathrm{C}$ (Faciola and Broderick, 2014).

\section{Sample Analysis}

Feed samples were analyzed for $\mathrm{CP}, \mathrm{NDF}$, and $\mathrm{ADF}$ by wet chemistry procedures (Cumberland Valley Analytical Services Inc., Maugansville, MD). Briefly, $\mathrm{CP}$ was determined according to AOAC International (2000) using method 990.03, ADF according to AOAC International (2000) method 973.18, and ash-free NDF according to Van Soest et al. (1991) using heat-stable amylase and sodium sulfite. Starch was determined by an enzymatic method (Karkalas, 1985; Hazyme, Centerchem, Norwalk, CT) after samples were gelatinized with sodium hydroxide. Total FA concentration and FA profile of feed samples was determined by GC after direct methylation (Sukhija and Palmquist, 1988), as described by Rico and Harvatine (2013). One milk sample was stored at $4^{\circ} \mathrm{C}$ with preservative (BronolabWII, Advanced Instruments Inc., Norwood, MA) until analyzed for fat and protein by Fourier transform infrared spectroscopy (Fossomatic 4000 Milko-Scan and 400 Fossomatic, Foss Electric, Hillerød, Denmark; at Dairy One Laboratory, Ithaca, NY). A second milk sample was immediately centrifuged at $3,000 \times g$ for 15 min at $4^{\circ} \mathrm{C}$ and fat cake was stored at $-20^{\circ} \mathrm{C}$ before analysis of FA composition, as described by Baldin et al. (2018). In short, FA were extracted in hexane isopropanol, base methylated with sodium methoxide, and quantified by GC with a fused-silica capillary column (SP-2560, 100 $\mathrm{m} \times 0.25 \mathrm{~mm}$ i.d. with $0.2-\mu \mathrm{m}$ film thickness; Supelco Inc., Bellefonte, PA) and a flame ionization detector.

Urine samples were thawed at room temperature and analyzed for allantoin (Chen et al., 1992), uric acid (Stanbio Uric Acid Kit 1045; Stanbio Laboratory Inc., San Antonio, TX), and creatinine (Cayman Kit 500701; Cayman Chemical, Ann Arbor, MI).

\section{Prediction of Microbial N Flow}

Secretion of C17:0 + C17:1 $(\mathrm{g} / \mathrm{d})$ in milk on d 28 and 35 of each period was calculated as milk C17:0 + C17:1 $(\mathrm{g} / 100 \mathrm{~g}$ of total FA $) \times$ milk FA yield $(\mathrm{g} / \mathrm{d})$. Duodenal flow of microbial purine bases was calculated as $=5.43$ $\times$ milk $\mathrm{C} 17: 0+\mathrm{C} 17: 1 \mathrm{~g} / \mathrm{d}$, and purine bases flow was converted to duodenal flow of microbial $\mathrm{N}$ assuming purine bases-to- $\mathrm{N}$ ratio in mixed rumen bacteria of 0.147 (Vlaeminck et al., 2005). The microbial N-to-OBCFA ratio was not determined in the current experiment and future experiments should determine this within 
the experiment using rumen digesta samples to correct for bias between treatments and account for variance in the marker ratio.

Daily volume of excreted urine was estimated based on urinary creatinine concentration, assuming a creatinine excretion rate of $29 \mathrm{mg} / \mathrm{kg}$ of BW (Hristov et al., 2011). Estimated urine output was used to calculate daily purine derivatives (allantoin and uric acid) excretions. Urinary purine derivatives excretion was used to estimate duodenal microbial $\mathrm{N}$ flow, as described in Hristov et al. (2009). A ratio of purine $\mathrm{N}$ to total $\mathrm{N}$ in rumen microorganisms of 0.134 was assumed based on the data of Valadares et al. (1999). The microbial Nto-purine ratio also was not determined in the current experiment, and future experiments should determine this within the experiment as discussed for the OBCFA ratio above.

\section{Statistical Analysis}

Data were analyzed as a crossover design using PROC MIXED of SAS with repeated measures (version 9.3; SAS Institute Inc., Cary, NC). A main goal was to test for a dietary risk by treatment interaction. A simple diet by treatment interaction could not be tested with the full data set because more observations were made during the low-risk phase than the moderate-risk phase. Therefore, for an accurate test of the interaction, the risk phases were analyzed independently. Specifically, d $7,14,21$, and 28 were included in 1 data set to represent the low-risk phase and a treatment by time interaction tested differences during adaptation. The interaction of treatment and MFD risk was tested in a second data set that included the last day of the low-risk period (d 28 ) and the observation during the high-risk period (d 35 ). Both models included the random effects of period, sequence, and cow nested within treatment and the fixed effects of treatment, experimental day, the interaction of treatment and experimental day, and the effects of the pretrial covariate measurement for the variable. No parity by treatment or 3-way interactions of parity, treatment, and time were observed. Cow nested within treatment was the subject and day was the repeated variable. The autoregressive heterogeneous (1) or autoregressive (1) covariance structure was used depending on model fit and the Kenward-Roger denom-

Table 2. Performance and milk composition of cows supplemented with 2-hydroxy-4-(methylthio)butanoate (HMTBa) in diets with low and moderate risk of biohydrogenation-induced milk fat depression (BH-MFD)

\begin{tabular}{|c|c|c|c|c|c|c|}
\hline \multirow[b]{2}{*}{ Risk of BH-MFD ${ }^{1}$} & \multicolumn{2}{|c|}{ Treatment $^{2}$} & \multirow[b]{2}{*}{ SEM } & \multicolumn{3}{|c|}{$P$-value ${ }^{3}$} \\
\hline & Control & HMTBa & & Treatment & Day & Treatment $\times$ day \\
\hline \multicolumn{7}{|c|}{ Low-risk phase (d 7 to 28 ) } \\
\hline $\mathrm{DMI}, \mathrm{kg} / \mathrm{d}$ & 30.2 & 29.9 & 0.44 & 0.22 & $<0.001$ & 0.19 \\
\hline \multicolumn{7}{|l|}{ Milk } \\
\hline Yield, kg/d & 37.4 & 37.1 & 1.90 & 0.52 & $<0.001$ & 0.19 \\
\hline Fat, \% & 3.92 & 3.94 & 0.10 & 0.62 & 0.07 & 0.95 \\
\hline Fat, $\mathrm{kg} / \mathrm{d}$ & 1.43 & 1.43 & 0.06 & 0.85 & 0.44 & 0.87 \\
\hline Protein, $\%$ & 3.25 & 3.24 & 0.06 & 0.17 & $<0.001$ & 0.17 \\
\hline Protein, kg/d & 1.20 & 1.19 & 0.05 & 0.46 & $<0.001$ & 0.51 \\
\hline $\mathrm{BW},{ }^{4} \mathrm{~kg}$ & 665 & 672 & 3.9 & 0.09 & - & - \\
\hline BW change, ${ }^{4,5} \mathrm{~kg}$ & 8.47 & 17.8 & 4.38 & 0.03 & - & - \\
\hline $\mathrm{BCS}^{4}$ & 2.8 & 2.8 & 0.02 & 0.31 & - & - \\
\hline \multicolumn{7}{|c|}{ Moderate-risk phase (d 35) } \\
\hline DMI, $\mathrm{kg} / \mathrm{d}$ & 30.5 & 30.5 & 0.47 & 0.93 & 0.28 & 0.43 \\
\hline \multicolumn{7}{|l|}{ Milk } \\
\hline Yield, kg/d & 39.2 & 38.6 & 0.84 & 0.45 & $<0.001$ & 0.60 \\
\hline Fat, $\%$ & 3.61 & 3.86 & 0.08 & $<0.01$ & $<0.001$ & 0.01 \\
\hline Fat, kg/d & 1.35 & 1.47 & 0.04 & $<0.01$ & 0.83 & $<0.001$ \\
\hline Protein, \% & 3.27 & 3.26 & 0.02 & 0.49 & 0.34 & 0.55 \\
\hline Protein, kg/d & 1.27 & 1.25 & 0.03 & 0.64 & $<0.001$ & 0.80 \\
\hline $\mathrm{BW}, \mathrm{kg}$ & 676 & 682 & 3.9 & 0.16 & - & - \\
\hline $\mathrm{BW}$ change, $\mathrm{kg}$ & 9.88 & 8.38 & 4.32 & 0.73 & - & - \\
\hline $\mathrm{BCS}^{6}$ & - & - & - & - & - & - \\
\hline
\end{tabular}

${ }^{1}$ Low-risk diet $=31.6 \%$ NDF, $21.8 \%$ starch, and $2.57 \%$ UFA. Moderate-risk diet $=28.7 \%$ NDF, $28.1 \%$ starch, and $3.48 \%$ UFA.

${ }^{2}$ Treatment was control (ground corn) or HMTBa ( $0.1 \%$ of diet DM provided in a ground corn carrier).

${ }^{3}$ Effect of treatment, experimental day, and their interaction. Data represent the LSM for the risk phase.

${ }^{4} \mathrm{BW}, \mathrm{BW}$ change, and BCS were analyzed as single measurements.

${ }^{5} \mathrm{BW}$ change from end of pretrial until end of low-risk phase (d 28) and BW change from end of low-risk phase until end of moderate-risk phase (d 35).

${ }^{6}$ Not determined. 
inator degrees of freedom adjustment was employed. The preplanned contrast tested the effect of HMTBa at each day. Data points with Studentized residuals outside of \pm 3.0 were considered outliers and excluded from analysis. The change in OBCFA (HMTBa relative to $\mathrm{CON}$ ) on d 28 and 35 was analyzed using proc ttest of SAS with the statements show H0, sides $=2$, and $\alpha=0.05$. Significant differences were declared at $P<$ 0.05 for main effects and $P<0.10$ for interactions, and tendencies were declared at $P<0.10$ for main effects and $P<0.15$ for interactions.

\section{RESULTS AND DISCUSSION}

Decreasing diet effective NDF and increasing starch and UFA is a well-established model to alter ruminal $\mathrm{BH}$ pathways and induce formation of bioactive FA that inhibit milk fat synthesis (Bauman and Griinari, 2003; Rico and Harvatine, 2013; Baldin et al., 2018). Increasing starch concentration from 21.8 to $28.1 \%$ and decreasing physically effective NDF from 19.6 to $16.0 \%$ of diet DM in the moderate-risk phase is expected to decrease rumen $\mathrm{pH}$ (Zebeli et al., 2007). Of note, other experiments have reported no effect of HMTBa on rumen pH (Lee et al., 2015).

Previous studies using a similar BH-induced MFD model demonstrated that changes in milk fat yield and milk FA composition (i.e., de novo FA synthesis and trans-10 C18:1) and changes in key microbial populations occur within 5 to $7 \mathrm{~d}$ (Rico and Harvatine, 2013; Rico et al., 2014, 2015). The current study further supports the fast adaptation of rumen microbes to changes in diet fermentability and UFA and supported the use short experimental periods (7-10 d) to investigate BHinduced MFD. It was recently demonstrated that HMTBa increased milk fat in situations with a moderate or high risk of BH-induced MFD (Baldin et al., 2018). The current experiment used a moderate-risk challenge (as \% of diet DM: starch $=28.0, \mathrm{UFA}=3.48$, and NDF $=28.7$ ) after adaptation to a low-risk diet, as it better represents on-farm scenarios where small modifications in the diet increase the risk of BH-induced MFD.

\section{Milk Fat Response}

We found no effect of treatment or treatment by day interaction for milk fat concentration and yield during the low-risk phase (Table 2). In fact, milk fat remained relatively unchanged on both treatments during the $28-d$ duration of the low-risk phase (Figure 1A and 1B). Lee et al. (2015) and Baldin et al. (2018) also did not observe a response to HMTBa supplementation when feeding diets with a low risk of MFD and low trans-10 C18:1 in milk fat. On the other hand, a treatment by day interaction was observed for milk fat concentration and yield during the moderate-risk phase (Table 2 ). Whereas control cows experienced a 0.36-percentage point decrease in milk fat content during the moderate-risk phase, HMTBa cows maintained higher milk fat concentration (d 35; 3.86 vs. 3.61\%, Figure 1A; Supplemental Table S1, https://doi.org/10.3168/ jds.2018-15031). Concomitantly, milk fat yield was 118 $\mathrm{g} / \mathrm{d}$ higher in HMTBa cows during the moderate-risk phase (Figure 1B). The observed milk fat response to

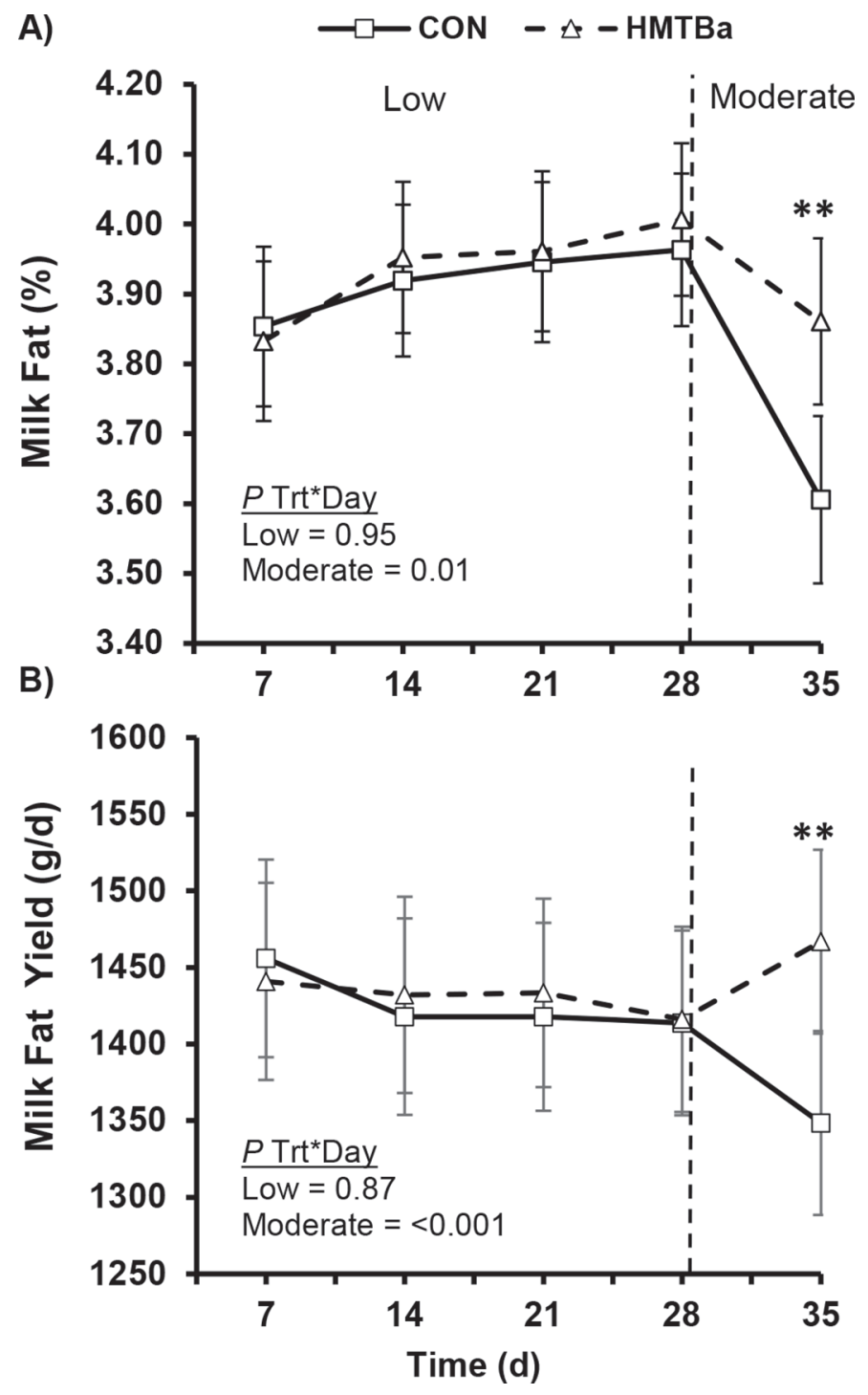

Figure 1. Effect of 2-hydroxy-4-(methylthio)butanoate (HMTBa, $0.1 \%$ of $\mathrm{DM})$ or unsupplemented control $(\mathrm{CON})$ on milk fat concentration (A) and yield (B) in cows receiving diets with low and moderate risk for biohydrogenation-induced milk fat depression. Effect of HMTBa at each sampling day is represented by asterisks $\left({ }^{*} P<0.05\right.$ and $\left.{ }^{* *} P<0.01\right)$. Data represent the LSM at each time point and error bars represent the SEM $(\mathrm{n}=36$ cows per treatment). Trt $=$ treatment. 
HMTBa is comparable to the 0.45 percentage point and $100 \mathrm{~g} / \mathrm{d}$ increase in milk fat content and yield, respectively, reported by Baldin et al. (2018) when feeding a diet with a moderate risk of BH-induced MFD. No effect of treatment or treatment by day interaction was observed for DMI, milk yield, and milk protein content and yield during the low- or moderate-risk phases (Table 2). Decreased milk fat with no changes in milk yield or yield of other components supports classical BH-induced MFD in the control (Harvatine et al., 2009).

\section{Milk FA Related to Rumen BH and MFD}

We noted a treatment by day interaction for milk fat trans-10 C18:1 concentration during the low-risk and moderate-risk phases (Table 3). Milk fat trans-10 C18:1 was slightly decreased by HMTBa only on the last day of the low-risk phase (d 28; 0.42 vs. $0.45 \mathrm{~g} / 100 \mathrm{~g}$ of FA, $P=0.03$, Figure 2A). During the moderate-risk phase, milk fat trans-10 C18:1 concentration in control was increased over $75 \%$ compared with HMTBa (d 35; 1.41 vs. $0.80 \mathrm{~g} / 100 \mathrm{~g}$ of FA, $P<0.001$, Figure $2 \mathrm{~A}$ ).

Trans-10 C18:1 is a major FA intermediate formed during altered rumen BH (Jenkins et al., 2008), and its concentration in milk can serve as a proxy to characterize BH. The substantial increase in trans-10 C18:1 in milk fat suggests that control cows experienced altered rumen $\mathrm{BH}$ during the moderate-risk phase. This finding supports recent results presented by Baldin et al. (2018), where HMTBa supplementation also reduced the shift to the altered trans-10 pathway that occurs during BH-induced MFD. Baldin et al. (2018) speculated that this apparent role for HMTBa in stabilizing rumen $\mathrm{BH}$ could be mediated either by an increase in microbial mass (an increase in $\mathrm{BH}$ capacity would be expected) or HMTBa may modify the microbial population and maintain key ruminal microbial species important to BH. Characterization of the microbial population was beyond the scope of the current experiment, and possible changes in microbial mass are discussed below.

We observed no overall effect of treatment or treatment by day interactions for milk fat trans-11 C18:1 and milk FA by source (de novo, mixed, and preformed) during the low- or moderate-risk phase (Table 3). Changes in individual FA during the low- or moderate-risk phase are reported in Supplemental Tables S2 and S3, respectively (https://doi.org/10.3168/jds.2018-15031).

\section{Milk and Urine Biomarkers of Microbial Nitrogen Flow}

The HMTBa treatment increased the concentration of total OBCFA in milk by $5.2 \%$ during the low-risk phase and $5.3 \%$ during the moderate-risk phase (Table 3). Individual milk OBCFA increased by HMTBa

Table 3. Effect of 2-hydroxy-4-(methylthio)butanoate (HMTBa) on milk fat concentration of selected fatty acids (FA) of cows fed diets with low and moderate risk of biohydrogenation-induced milk fat depression (BH$\mathrm{MFD})^{1}$

\begin{tabular}{|c|c|c|c|c|c|c|}
\hline \multirow[b]{2}{*}{ Total FA, ${ }^{2} \mathrm{~g} / 100 \mathrm{~g}$} & \multicolumn{2}{|c|}{ Treatment $^{3}$} & \multirow[b]{2}{*}{ SEM } & \multicolumn{3}{|c|}{$P$-value ${ }^{4}$} \\
\hline & Control & HMTBa & & Treatment & Day & Treatment $\times$ day \\
\hline \multicolumn{7}{|l|}{ Low-risk phase } \\
\hline trans-10 C18:1 & 0.43 & 0.42 & 0.01 & 0.10 & $<0.001$ & 0.02 \\
\hline trans-11 C18:1 & 0.79 & 0.80 & 0.02 & 0.51 & 0.05 & 0.38 \\
\hline De novo FA & 27.4 & 27.5 & 0.16 & 0.26 & $<0.001$ & 0.91 \\
\hline Mixed FA & 29.7 & 29.8 & 0.27 & 0.82 & 0.05 & 0.92 \\
\hline Preformed FA & 36.4 & 36.8 & 0.33 & 0.13 & $<0.001$ & 0.18 \\
\hline Total OBCFA ${ }^{5}$ & 3.83 & 4.03 & 0.13 & $<0.001$ & $<0.01$ & 0.18 \\
\hline \multicolumn{7}{|l|}{ Moderate-risk phase } \\
\hline trans-10 C18:1 & 0.93 & 0.61 & 0.13 & 0.04 & $<0.001$ & 0.07 \\
\hline trans-11 C18:1 & 1.36 & 1.41 & 0.07 & 0.60 & $<0.001$ & 0.78 \\
\hline De novo FA & 26.1 & 26.4 & 0.21 & 0.17 & $<0.001$ & 0.83 \\
\hline Mixed FA & 27.5 & 27.6 & 0.23 & 0.51 & $<0.001$ & 0.65 \\
\hline Preformed FA & 39.7 & 40.0 & 0.31 & 0.26 & $<0.001$ & 0.97 \\
\hline Total OBCFA ${ }^{5}$ & 3.58 & 3.78 & 0.14 & $<0.001$ & $<0.001$ & 0.44 \\
\hline
\end{tabular}

${ }^{1}$ Low-risk diet $=31.6 \%$ NDF, $21.8 \%$ starch, and $2.57 \%$ UFA. Moderate-risk diet $=28.7 \%$ NDF, $28.1 \%$ starch, and $3.48 \%$ UFA.

${ }^{2}$ De novo FA $(<16 \mathrm{C})$ are synthesized by the mammary gland; preformed FA $(>16 \mathrm{C})$ originate from extraction from plasma; and mixed FA $(16 \mathrm{C})$ originate from both sources.

${ }^{3}$ Treatment was control (ground corn) or HMTBa ( $0.1 \%$ of diet DM provided in a ground corn carrier).

${ }^{4}$ Effect of treatment, experimental day, and their interaction. Data represent the LSM for the risk phase.

${ }^{5}$ Odd- and branched-chain fatty acids. Sum of C11:0, iso C13:0, anteiso C13:0, C13:0, iso C14:0, iso C15:0, anteiso $\mathrm{C} 15: 0, \mathrm{C} 15: 0$, iso $\mathrm{C} 16: 0$, iso $\mathrm{C} 17: 0$, anteiso $\mathrm{C} 17: 0, \mathrm{C} 17: 0$, and $\mathrm{C} 17: 1$. 
included C11:0 (10.5\%), C13:0 (9.8\%), anteiso C15:0 (1.8\%), C15:0 (9.8\%), C17:0 (5.4\%), and cis-9 C17:1 (5.2\%, Supplemental Table S2, https://doi.org/10 $.3168 /$ jds.2018-15031). During the moderate-risk phase (d 35), remarkable increases relative to control were observed for $\mathrm{C} 11: 0$ (19.4\%), iso $\mathrm{C} 13: 0$ (19.4\%), iso C14:0 (14.1\%), iso C15:0 (8.3\%), anteiso C15:0 (8.3\%), iso $\mathrm{C} 16: 0$ (13.0\%), and cis-9 C17:1 (5.3\%, Figure 3). Milk OBCFA were not reported in early studies that observed increased milk fat when adding HMTBa to highly fermentable diets (Rosser et al., 1971; Huber et al., 1984). Recently, 9.1 and $20 \%$ increases in the content of $\mathrm{C} 15: 0$ and $\mathrm{C} 17: 1$ in milk fat, respectively, occurred when feeding $25 \mathrm{~g} / \mathrm{d}$ of HMTBa in a low-risk diet (Lee et al., 2015). Increases in total OBCFA (9.0\%) and $\mathrm{C} 17: 0(9.3 \%)$ in milk due to HMTBa have also been observed when feeding a diet with high risk for BH-induced MFD (Baldin et al., 2018). Altogether, it appears that HMTBa increases, at varying levels, the concentration and secretion of OBCFA (mostly C15:0, $\mathrm{C} 17: 0$, and $\mathrm{C} 17: 1)$ in milk.

Odd- and branched-chain FA are not found in plants or feeds, but rumen bacteria have a high enrichment of OBCFA in their membrane lipids (Kaneda, 1991). Duodenal flow of some OBCFA has been reported to be lower than milk production, indicating postruminal synthesis from odd- and branched-chain VFA (Vlaeminck et al., 2015), although the extent of postruminal synthesis is not clear without methods that allow quantification, such as tracer approaches. French et al. (2012) also reported that ruminal infusion of isovalerate and 2-methylbutyrate had little effect on milk fat OBCFA. Nonetheless, the OBCFA profile of milk is expected to adequately reflect the OBCFA profile available for digestion in the small intestine (MassartLeën et al., 1983; Vlaeminck et al., 2015). Hence, under the assumption that milk OBCFA are predominantly of microbial origin, these FA have been proposed as potential biomarkers of duodenal flow of microbial $\mathrm{N}$ (Cabrita et al., 2003; Vlaeminck et al., 2005). Remarkably, the effectiveness of HMTBa in increasing milk OBCFA appears to be sustained even in adverse diets (i.e., low NDF, high starch, and high UFA).

In Vlaeminck et al. (2005), milk secretion of OBCFA showed potential to indirectly predict duodenal flow of microbial $\mathrm{N}$ in lactating cows. Interestingly, best fitting of the data was achieved with predictions based on milk secretion of 17-carbon FA only (C17:0 + cis-9 C17:1, equation 6 in Vlaeminck et al., 2005). In the current study, HMTBa increased milk secretion of C17:0 + cis9 C17:1 by 6.0 and $13.0 \%$ in the low- and moderate-risk phases, respectively (Table 4). Because of the linear nature of the $\mathrm{C} 17$ model proposed by Vlaeminck et al. (2005), the increase in milk secretion of C17 FA would have resulted in $6.6 \%(24.5 \mathrm{~g} / \mathrm{d})$ and $12.3 \%(38.9 \mathrm{~g} / \mathrm{d})$ greater predicted duodenal flow of microbial $\mathrm{N}$ when cows received HMTBa in the low- and moderate-risk phases, respectively (Table 4). Of note, the milk C17 model does not distinguish whether or not supplementation with HMTBa could have altered membrane lipid composition (i.e., 17-carbon FA) of rumen bacteria. The microbial protein-to-C17 ratio was not determined in the current experiment, but is suggested in future
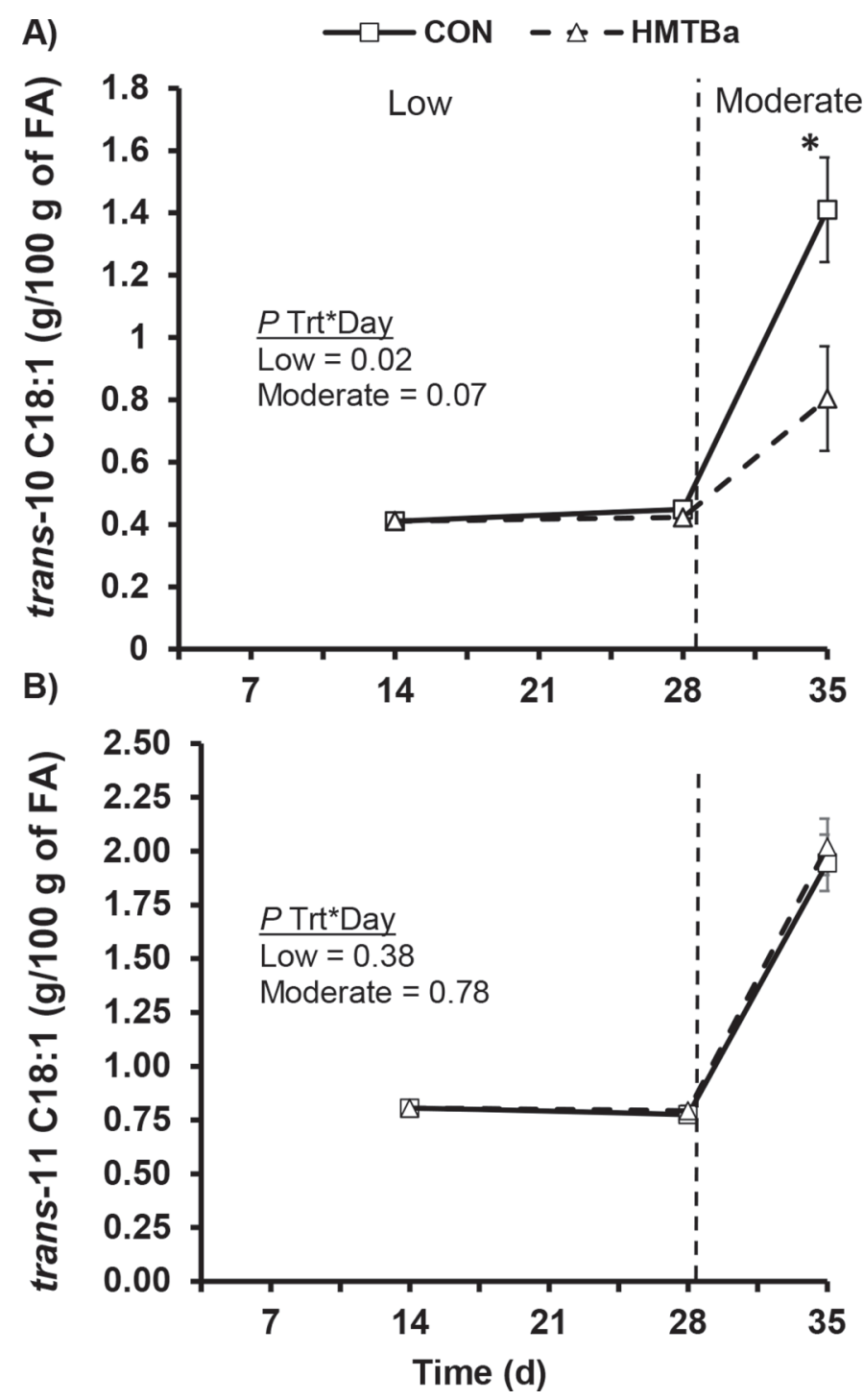

Figure 2. Effect of 2-hydroxy-4-(methylthio)butanoate (HMTBa; $0.1 \% \mathrm{DM})$ or unsupplemented control (CON) on the milk concentration of the predominant isomers of the alternate (trans-10 C18:1; A) and the normal (trans-11 C18:1; B) biohydrogenation pathways in cows receiving diets with low and moderate risk for biohydrogenationinduced milk fat depression. Effect of HMTBa at each sampling day is represented by asterisks ${ }^{*} P<0.05$ and $\left.{ }^{* *} P<0.01\right)$. Data represent the LSM at each time point and error bars represent the SEM $(\mathrm{n}=36$ cows per treatment). $\mathrm{FA}=$ fatty acid; Trt $=$ treatment. 


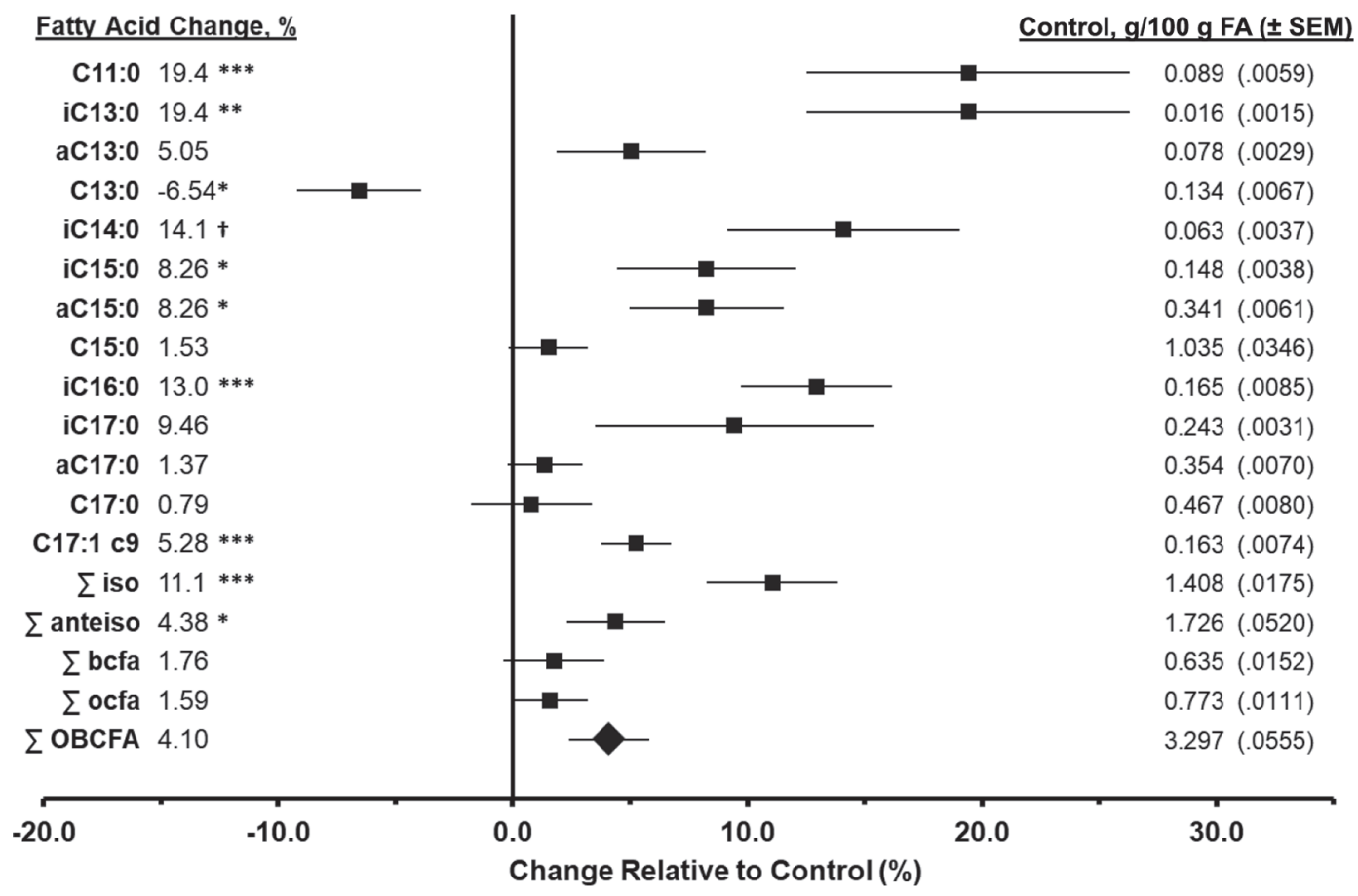

Figure 3. Effect of 2-hydroxy-4-(methylthio)butanoate (HMTBa; 0.1\% DM) on the milk concentration of odd- and branched-chain fatty acids (OBCFA) at the end of the moderate-risk phase (d 35) for biohydrogenation-induced milk fat depression. Change relative to control cal-

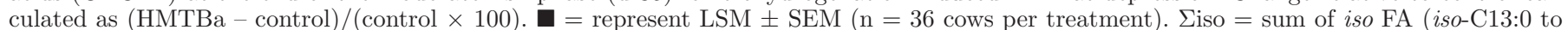
iso-C17:0); Eanteiso = sum of anteiso FA (anteiso-C13:0 to anteiso-C17:0); $\Sigma$ bcfa $=$ sum of all branched-chain FA; $\Sigma$ ocfa $=$ sum of all odd-chain FA; $\Sigma$ OBCFA $=$ sum of all branched- and odd-chain FA. Significance of change shown by $\dagger P<0.1,{ }^{*} P<0.05,{ }^{* *} P<0.01,{ }^{* * *} P<0.001$. FA $=$ fatty acids; $\mathrm{a}=$ anteiso $\mathrm{i}=i$ so $; \mathrm{c}=$ cis.

work, as it would account for a possible bias between diets and provide insight into the variance of this ratio.

When a second indirect model was used based on excretion of purine derivatives in urine (Hristov et al., 2009), prediction of microbial $\mathrm{N}$ flow did not differ between treatments (Table 4). The lack of difference when using the later model was mainly because the treatments did not differ in BW, BW change, or total excretion of urinary purine derivatives in either of the 2 dietary phases (Table 2). However, the equation used failed to account for HMTBa potentially shifting the bacterial purine bases-to- $\mathrm{N}$ ratio, and determination of the ratio is suggested in future experiments. Also of note, Tebbe and Weiss (2018) recently demonstrated that the rate of creatinine excretion per unit of BW varies considerably among cows. Additionally, day-today variation in urine volume could also have affected accuracy and precision of spot sampling (Shingfield and Offer, 1998). Altogether, the assumptions associated with milk and urine biomarkers could likely explain the discrepancy in microbial $\mathrm{N}$ flow predicted between the 2 methods (Table 4 ).

The concept of using milk OBCFA as biomarkers of microbial $\mathrm{N}$ flow has been questioned and needs verification under various dietary regimens (Dewhurst et al.,
2007). For example, partitioning of FA toward adipose tissue during MFD could have resulted in an underestimation of duodenal OBCFA from milk OBCFA in the control treatment. Nonetheless, the predictions of microbial $\mathrm{N}$ flow based on milk OBCFA in the current study are in agreement with increased microbial $\mathrm{N}$ outflow from the rumen when cows were fed a similar amount of HMTBa (Lee et al., 2015). It is plausible that the role of HMTBa in stabilizing rumen BH (i.e., reduce the shift to altered trans-10 pathway) could be related to increased microbial mass, which in turn is expected to increase BH capacity. The biological mechanism for this microbial stimulation is not clear. Insufficient data exist to accept or reject this hypothesis, but assessment of rumen BH when supplementing HMTBa to MFD diets would be beneficial.

\section{CONCLUSIONS}

Results from this study verified that HMTBa attenuates BH-induced MFD caused by increased dietary UFA concentration and carbohydrate fermentability. Lower concentration of trans-10 C18:1 in milk of HMTBa-fed cows supported a role for HMTBa in stabilizing rumen $\mathrm{BH}$ and preventing the shift to the altered $\mathrm{BH}$ pathway 
Table 4. Predicted duodenal flow of microbial $\mathrm{N}$ in cows supplemented with 2-hydroxy-4-(methylthio) butanoate (HMTBa) in diets with low and moderate risk of biohydrogenation-induced milk fat depression (BH-MFD)

\begin{tabular}{|c|c|c|c|c|c|}
\hline \multirow[b]{2}{*}{ Item } & \multirow{2}{*}{$\begin{array}{l}\text { Risk of } \\
\text { BH-MFD }^{1}\end{array}$} & \multicolumn{2}{|c|}{ Treatment $^{2}$} & \multirow[b]{2}{*}{ SEM } & \multirow[b]{2}{*}{$P$-value } \\
\hline & & Control & НMTBa & & \\
\hline \multicolumn{6}{|l|}{ Based on milk biomarkers } \\
\hline \multirow{2}{*}{ Milk C17:0+C17:1, g/d } & Low & 10.0 & 10.6 & 0.20 & $<0.001$ \\
\hline & Moderate & 8.49 & 9.59 & 0.29 & $<0.001$ \\
\hline \multicolumn{6}{|l|}{ Predicted duodenal flow, $\mathrm{g} / \mathrm{d}$} \\
\hline \multirow[t]{2}{*}{ Microbial purine bases } & Low & 54.48 & 58.09 & 1.08 & $<0.01$ \\
\hline & Moderate & 46.53 & 52.25 & 1.25 & $<0.001$ \\
\hline \multirow[t]{2}{*}{ Microbial $\mathrm{N}^{3}$} & Low & 370.7 & 395.2 & 7.35 & $<0.01$ \\
\hline & Moderate & 316.6 & 355.5 & 8.50 & $<0.001$ \\
\hline \multicolumn{6}{|l|}{ Based on urine biomarkers } \\
\hline \multicolumn{6}{|l|}{ Urine, $\mathrm{mmol} / \mathrm{d}$} \\
\hline \multirow{2}{*}{ Allantoin } & Low & 587 & 595 & 13.4 & 0.54 \\
\hline & Moderate & 611 & 600 & 13.6 & 0.44 \\
\hline \multirow[t]{2}{*}{ Uric acid } & Low & 65.9 & 56.2 & 2.17 & $<0.001$ \\
\hline & Moderate & 62.8 & 58.9 & 2.17 & 0.07 \\
\hline \multirow[t]{2}{*}{ Total purine derivatives } & Low & 653 & 651 & 14.8 & 0.92 \\
\hline & Moderate & 667 & 659 & 15.0 & 0.61 \\
\hline \multirow{3}{*}{$\begin{array}{l}\text { Predicted duodenal flow, } \mathrm{g} / \mathrm{d} \\
\text { Microbial } \mathrm{N}^{4}\end{array}$} & & & & & \\
\hline & Low & 446 & 445 & 10.9 & 0.90 \\
\hline & Moderate & 456 & 450 & 11.0 & 0.59 \\
\hline \multirow{3}{*}{\multicolumn{6}{|c|}{$\begin{array}{l}{ }^{1} \text { Low-risk diet }=31.6 \% \text { NDF, } 21.8 \% \text { starch, and } 2.57 \% \text { UFA. Moderate-risk diet }=28.7 \% \text { NDF, } 28.1 \% \text { starch } \\
\text { and } 3.48 \% \text { UFA. } \\
{ }^{2} \text { Treatment was control (ground corn) or HMTBa }(0.1 \% \text { of diet DM provided in a ground corn carrier). } \\
{ }^{3} \text { Duodenal flow of microbial purine bases calculated as }=5.43 \times \text { milk } \mathrm{C} 17: 0+\mathrm{C} 17: 1 \mathrm{~g} / \mathrm{d} \text { and duodenal flor } \\
\text { of microbial N calculated assuming purine bases to N ratio in mixed rumen bacteria of } 0.147 \text { (Vlaeminck e } \\
\text { al., 2005). }\end{array}$}} \\
\hline & & & & & \\
\hline & & & & & \\
\hline \multicolumn{6}{|c|}{${ }^{4}$ Estimated based on urinary purine derivatives excretion as described in Hristov et al. (2009). } \\
\hline
\end{tabular}

that causes MFD. No milk fat response to HMTBa was observed when feeding a diet with a low risk for MFD. The HMTBa also increased the concentration and secretion of milk fat biomarkers of microbial $\mathrm{N}$ flow (i.e., OBCFA) when feeding the low- or moderate-risk diet for MFD, but urine biomarkers of microbial $\mathrm{N}$ flow (i.e., purine derivatives) were not affected by HMTBa. However, both markers have associated limitations, and a microbial N-to-marker ratio would improve predictions but was not determined in the current experiment. The observed milk fat response substantiates the feeding of HMTBa to prevent or attenuate BH-induced MFD on farms.

\section{ACKNOWLEDGMENTS}

This project was partially supported by Novus International (St. Charles, MO). The authors gratefully acknowledge the technical assistance of N. Urrutia and Jackie Ying (Penn State University, University Park, PA). The help of students in the Harvatine Laboratory (Isaac Salfer, Rebecca Bomberger, Noah Shulman, Elizabeth Palmer, Jocely Souza, and Anna Haggenstaller, Penn State University, University Park) is also greatly appreciated. Gratitude is also expressed to the staff at the Pennsylvania State University Dairy Cattle Research and Education Center. This project was partially supported by Penn State University including USDA National Institute of Food and Agriculture Federal Appropriations under Project number PEN04539 and accession number 1000803.

\section{REFERENCES}

AOAC International. 2000. Official Methods of Analysis. 17th ed. AOAC Int., Arlington, VA.

Baldin, M., G. Zanton, and K. Harvatine. 2018. Effect of 2-hydroxy4-(methylthio) butanoate (HMTBa) on risk of biohydrogenationinduced milk fat depression. J. Dairy Sci. 101:376-385.

Bauman, D. E., and J. M. Griinari. 2003. Nutritional regulation of milk fat synthesis. Annu. Rev. Nutr. 23:203-227.

Bolotova, Y. V. 2016. An analysis of milk pricing in the United States dairy industry. Agribusiness 33:194-208.

Broderick, G. A., and N. R. Merchen. 1992. Markers for quantifying microbial protein synthesis in the rumen. J. Dairy Sci. 75:2618 2632.

Cabrita, A. R., A. Fonseca, R. Dewhurst, and E. Gomes. 2003. Nitrogen supplementation of corn silages. 2. Assessing rumen function using fatty acid profiles of bovine milk. J. Dairy Sci. 86:4020-4032.

Chen, X. B., Y. Chen, M. Franklin, E. Orskov, and W. Shand. 1992. The effect of feed intake and body weight on purine derivative excretion and microbial protein supply in sheep. J. Anim. Sci. 70:1534-1542.

Dewhurst, R. J., J. Moorby, B. Vlaeminck, and V. Fievez. 2007. Apparent recovery of duodenal odd-and branched-chain fatty acids in milk of dairy cows. J. Dairy Sci. 90:1775-1780. 
Faciola, A. P., and G. Broderick. 2014. Effects of feeding lauric acid or coconut oil on ruminal protozoa numbers, fermentation pattern, digestion, omasal nutrient flow, and milk production in dairy cows. J. Dairy Sci. 97:5088-5100.

Firkins, J. L., A. N. Hristov, M. B. Hall, G. A. Varga, and N. R. StPierre. 2006. Integration of ruminal metabolism in dairy cattle. J. Dairy Sci. 89(E. Suppl.):E31-E51.

French, E. A., S. Bertics, and L. Armentano. 2012. Rumen and milk odd-and branched-chain fatty acid proportions are minimally influenced by ruminal volatile fatty acid infusions. J. Dairy Sci. 95:2015-2026.

Harvatine, K. J., J. W. Perfield, and D. E. Bauman. 2009. Expression of enzymes and key regulators of lipid synthesis is upregulated in adipose tissue during CLA-induced milk fat depression in dairy cows. J. Nutr. 139:849-854.

Hristov, A. N., C. Lee, T. Cassidy, M. Long, K. Heyler, B. Corl, and R. Forster. 2011. Effects of lauric and myristic acids on ruminal fermentation, production, and milk fatty acid composition in lactating dairy cows. J. Dairy Sci. 94:382-395.

Hristov, A. N., M. Vander Pol, M. Agle, S. Zaman, C. Schneider, P. Ndegwa, V. Vaddella, K. Johnson, K. J. Shingfield, and S. Karnati. 2009. Effect of lauric acid and coconut oil on ruminal fermentation, digestion, ammonia losses from manure, and milk fatty acid composition in lactating cows. J. Dairy Sci. 92:5561-5582.

Huber, J. T., R. Emery, W. Bergen, J. Liesman, L. Kung, K. King, R. Gardner, and M. Checketts. 1984. Influences of methionine hydroxy analog on milk and milk fat production, blood serum lipids, and plasma amino acids. J. Dairy Sci. 67:2525-2531.

Jenkins, T. C., R. Wallace, P. Moate, and E. Mosley. 2008. Boardinvited review: Recent advances in biohydrogenation of unsaturated fatty acids within the rumen microbial ecosystem. J. Anim. Sci. 86:397-412.

Kaneda, T. 1991. Iso- and anteiso-fatty acids in bacteria: Biosynthesis, function, and taxonomic significance. Microbiol. Rev. 55:288-302.

Karkalas, J. 1985. An improved enzymic method for the determination of native and modified starch. J. Sci. Food Agric. 36:1019-1027.

Kononoff, P. J., A. J. Heinrichs, and D. R. Buckmaster. 2003. Modification of the Penn State forage and total mixed ration particle separator and the effects of moisture content on its measurements. J. Dairy Sci. 86:1858-1863.

Lee, C., J. Oh, A. Hristov, K. Harvatine, M. Vazquez-Anon, and G. Zanton. 2015. Effect of 2-hydroxy-4-methylthio-butanoic acid on ruminal fermentation, bacterial distribution, digestibility, and performance of lactating dairy cows. J. Dairy Sci. 98:1234-1247.

Massart-Leën, A. M., E. Roets, G. Peeters, and R. Verbeke. 1983 Propionate for fatty acid synthesis by the mammary gland of the lactating goat. J. Dairy Sci. 66:1445-1454.

McKain, N., K. J. Shingfield, and R. J. Wallace. 2010. Metabolism of conjugated linoleic acids and 18:1 fatty acids by ruminal bacteria: products and mechanism. Microbiology 156:579-588.
Rico, D. E., and K. J. Harvatine. 2013. Induction of and recovery from milk fat depression occurs progressively in dairy cows switched between diets that differ in fiber and oil concentration. J. Dairy Sci. 96:6621-6630.

Rico, D. E., A. Holloway, and K. Harvatine. 2014. Effect of monensin on recovery from diet-induced milk fat depression. J. Dairy Sci. 97:2376-2386.

Rico, D. E., S. Preston, J. Risser, and K. Harvatine. 2015. Rapid changes in key ruminal microbial populations during the induction of and recovery from diet-induced milk fat depression in dairy cows. Br. J. Nutr. 114:358-367.

Rosser, R., C. Polan, P. Chandler, and T. Bibb. 1971. Effects of whey components and methionine analog on bovine milk fat production. J. Dairy Sci. 54:1807-1816.

Shingfield, K., and N. Offer. 1998. Evaluation of the spot urine sampling technique to assess urinary purine derivative excretion in lactating dairy cows. Anim. Sci. 66:557-568.

Sukhija, P. S., and D. Palmquist. 1988. Rapid method for determination of total fatty acid content and composition of feedstuffs and feces. J. Agric. Food Chem. 36:1202-1206.

Tebbe, A. W., and W. P. Weiss. 2018. Evaluation of creatinine as a urine marker and factors affecting urinary excretion of magnesium by dairy cows. J. Dairy Sci. 101:5020-5032.

Valadares, R. F., G. Broderick, S. Valadares Filho, and M. Clayton. 1999. Effect of replacing alfalfa silage with high moisture corn on ruminal protein synthesis estimated from excretion of total purine derivatives. J. Dairy Sci. 82:2686-2696.

Van Soest, P. J., J. Robertson, and B. Lewis. 1991. Methods for dietary fiber, neutral detergent fiber, and nonstarch polysaccharides in relation to animal nutrition. J. Dairy Sci. 74:3583-3597.

Vázquez-Añón, M., T. Cassidy, P. McCullough, and G. Varga. 2001. Effects of alimet on nutrient digestibility, bacterial protein synthesis, and ruminal disappearance during continuous culture. J. Dairy Sci. 84:159-166

Vlaeminck, B., C. Dufour, A. Van Vuuren, A. Cabrita, R. Dewhurst, D. Demeyer, and V. Fievez. 2005. Use of odd and branched-chain fatty acids in rumen contents and milk as a potential microbial marker. J. Dairy Sci. 88:1031-1042.

Vlaeminck, B., R. Gervais, M. M. Rahman, F. Gadeyne, M. Gorniak, M. Doreau, and V. Fievez. 2015. Postruminal synthesis modifies the odd-and branched-chain fatty acid profile from the duodenum to milk. J. Dairy Sci. 98:4829-4840.

Wildman, E., G. Jones, P. Wagner, R. Boman, H. Troutt, and T. Lesch. 1982. A dairy cow body condition scoring system and its relationship to selected production characteristics. J. Dairy Sci. 65:495-501.

Zebeli, Q., M. Tafaj, I. Weber, J. Dijkstra, H. Steingass, and W. Drochner. 2007. Effects of varying dietary forage particle size in two concentrate levels on chewing activity, ruminal mat characteristics, and passage in dairy cows. J. Dairy Sci. 90:1929-1942. 